\title{
Use of brewer's yeast (Saccharomyces cerevisiae) in broiler feeds to replace corn gluten meal with or without probiotic additives
}

\author{
Georgeta Ciurescu *1, Mihaela Dumitru ${ }^{1}$, Anca Gheorghe 1 \\ *Corresponding author: ciurescugeorgeta@yahoo.com
}

${ }^{1}$ Laboratory of Animal Nutrition, National Research \& Development Institute for Biology and Animal Nutrition, Calea București no.1, Balotești, 077015, Ilfov, Romania

\section{ABSTRACT}

This study was intended to assess the effect of graded replacements of corn gluten meal with Brewer's yeast (Saccharomyces cerevisiae), with and without Bacillus megaterium supplementation, on performance, carcass characteristics, and the gut broilers microflora composition. A total of 720 mixed sex one-day-old broiler chicks (Ross 308 ) were randomly assigned to six dietary treatment groups (6 replicates each) in a $3 \times 2$ factorial arrangement, including 3 levels of Brewer's yeast (BY; 0, 25, and 50\%, to replace corn gluten meal; CGM) in the presence $(+)$ or absence $(-)$ of $B$. megaterium used as probiotic (Pro). The results showed that broilers fed diets containing BY up to $25 \%$ had comparable body weight (BWG), feed intake (FI), and feed conversion ratio (FCR) to the birds fed only CGM, over the entire feeding period (days 1-35). Conversely, higher levels of BY $(50 \%$ replacing CGM) registered the lowest BWG values $(\mathrm{P}<0.001)$ and impaired FCR $(P<0.010)$, but without effects on FI. The BY diets did not significantly affect the main broiler's carcass traits. The diets with Pro did not involve modifications on carcass and organs size, but a tendency to increase the gizzard weight $(\mathrm{P}=0.094)$ and to decrease SIL $(\mathrm{P}=0.076)$ was observed. Pro addition also, reduced the cecal $\mathrm{pH}(\mathrm{P}=0.040)$ and diminish the total coliforms $(\mathrm{P}<0.010)$, Clostridium spp. $(P<0.0001)$, and E. coli $(\mathrm{P}<0.0001)$ count, whereas LAB, Bacillus spp., and Enterococcus spp. bacteria were increased $(\mathrm{P}=0.022 ; \mathrm{P}<0.0001$, and $\mathrm{P}<0.0001$, respectively).

Keywords: Broiler, Bacillus megaterium, performance, microflora, Saccharomyces cerevisiae

\section{INTRODUCTION}

The natural growth promoting products administration in poultry nutrition is on the rise due to the ban on antibiotics in feed by the European Union (EU). Moreover, the use of antibiotics in animal feed has been 
reported to intensify antimicrobial resistance, and this has made nutritionists search for natural alternatives to antibiotics. Probiotics, which are live cultures of harmless bacteria or yeast species, have been increasingly adopted as an alternative to antibiotic growth promoters in poultry diets (Gadde et al., 2017). Several studies revealed that supplementation of probiotics such as live bacteria (Bacillus coagulans, $B$. subtilis, B. licheniformis, and B. amyloliquefaciens), and yeast (Saccharomyces cerevisiae) have positive impacts on growth, feed efficiency, and utilization (Mountzouris et al., 2010; Silva et al., 2010; Sen et al., 2012; Park and Kim, 2014; Zhen et al. 2018). Furthermore, the addition of probiotics to feed and/or water for chickens involved a significant effect by modulation of the composition and intestinal microbiota profile (Mountzouris et al., 2007).

In the last couple of decades, brewer's/baker's yeast (Saccharomyces cerevisiae) one of such natural substitutes in animal production, received great consideration. Yeast addition to livestock or poultry feeds has been known to improve animals' growth performance (GP) and health (Kim et al., 2011; Muthusamy et al., 2011; Chen et al., 2017; Chollom et al., 2017; Zhou et al., 2018; Ogbuewu et al., 2019; Ahiwe et al., 2020). Yeast and its derivatives, as prebiotics (dead/autolyzed) or probiotics (live), have biologically valuable nutrients such as proteins, vitamins, trace minerals, polysaccharides and several other beneficial factors (dos Santos Mathias et al., 2014; Amorim et al., 2016; Elghandour et al., 2019). It has also been reported that B. subtilis, yeast and their combination improved the intestinal health of broilers and could be potential alternatives to antibiotics (Li et al., 2017). Very recently, we have demonstrated that supplementation with $B$. subtilis increased the feed efficiency and reduced pathogens (E. coli) in the gastrointestinal tract (GIT) and excreta of broiler chickens (Ciurescu et al., 2020). To our knowledge, no studies have been previously performed to investigate the effects of Brewer's yeast (BY; Saccharomyces cerevisiae) to replace corn gluten meal (CGM) on broiler performance. Thus, the present study was intended to investigate a suitable addition level of BY in chicks' diet as a substitute protein source for a replacement for CGM. The other objectives of the experiment were to evaluate the efficacy of the BY with or without Bacillus megaterium, as a probiotic, on the growth performance, carcass traits, GIT, and excreta microflora in broilers.

\section{MATERIALS AND METHODS}

The Animal Ethics Committee approved the experimental protocol of the National Research-Development Institute for Biology and Animal Nutrition (INCDBNA-IBNA) Balotești, Romania. According to International Guidelines for investigate involving animals (Directive2010/63/EU), the care and 
handling of the birds from the present trial was completed to maintain the rights, welfare, and cause them as little stress as possible.

\section{Probiotic Strain}

Brewer's yeast (Saccharomyces cerevisiae) was screened in the Biotechnology Lab, from INCDBNA-IBNA Balotești. S. cerevisiae was aerobically cultured in medium (g/L) containing malt powder 20 , glucose 10 , yeast powder 10 , and incubated at $28^{\circ} \mathrm{C}$ for $48 \mathrm{~h}$. The culture registered a concentration of $1 \times 10^{\circ} \mathrm{CFU} / \mathrm{g}$.

A bacteria strain isolated from soil and identified as Bacillus megaterium was used as source of probiotics in the field trial. The strain was stored at $-80^{\circ} \mathrm{C}$ in a nutrient medium $(\mathrm{g} / \mathrm{L}$ : tryptone 10 ; meat extract 5 ; sodium chloride 5 ; pH value $7.2 \pm 2$ ) with $20 \%$ sterile glycerol and deposited in the Collection of INCDBNA-IBNA Balotești, Romania, under the code IBNA 66. The new strain was mixed in the drinking water of chicks. $B$. megaterium was prepared daily and fresh culture was provided through drinking water in a concentration of $5 \times 10^{11} \mathrm{CFU} \mathrm{mL}^{-1}$. The chicks were provided water plus $1 \mathrm{~mL}$ of $B$. megaterium suspensions per litter of ratio. The probiotics properties of $B$. megaterium were evaluated in vitro in our Lab (data not shown; Dumitru et al., 2021 in press).

\section{Experimental Design, Animals, Diets, and Management}

Seven hundred and twenty unsexed day-old Ross 308 broiler chicks were weighed and equally divided among 6 dietary treatments with six replicates (20 chicks each). Brewer's yeast in graded levels $(0,25$ or $50 \%$, to replace CGM) was tested with (+) or without (-) of Bacillus megaterium used as probiotic (Pro) in a $3 \times 2$ factorial arrangement of treatments in a completely randomized design. Chemical composition of BY $(S$. cerevisiae inactivated by drying, containing $1 \times 10^{9} \mathrm{CFU}$ active per g) and CGM is shown in Table 1. The program of feeding was separated into starter (days 1-10) and grower (days 11-35) phases. Each feeding diets were formulated to be isonitrogenous, isocaloric, and with similar total lysine content, total sulphur amino acids (TSAA; Table 2), calcium and available phosphorous. All the nutrients met or exceed the nutrient requirements as recommended by guidelines Ross 308, Aviagen Ltd., Midlothian, UK. Diets were manufactured in mash form, without the inclusion of growth promoters/ antibiotics. However, narasin as a coccidiostat (Monteban G100, Elanco $\mathrm{GmbH}$ ) and phytase (Axtra PHY 5,000 L, Danisco Animal Nutrition, Marlborough, UK; 0.2 $\mathrm{g} / \mathrm{kg}$ diet, respectively) as exogenous enzymes to maximize the feed utilization, were included in diets. Feed and water were given ad libitum. Broilers were raised in a temperature-controlled room with identical size of pens $(1.75 \times 1.55 \mathrm{~m})$. In the first $5 \mathrm{~d}$, the room temperature was maintained at $34^{\circ} \mathrm{C}$, follow by a slowly reduced in accordance to standard management 
practices until of $22^{\circ} \mathrm{C}$ by using thermostatically controlled heaters, fans, and regulable sidewall inlets. According to EU legislation (EU Council Directive $2007 / 43 / E C$ ) starting with 1D to 7D, the light was insured for $23 \mathrm{~h} / \mathrm{d}$ and from 8D, the light was reduced by $1 \mathrm{~h}$ a day until $20 \mathrm{~h}$. Broilers were immunized at the hatch for Marek's, Newcastle, and Infectious Bronchitis Disease. The overall trial was 35 days.

Table 1. Comparison of the nutritional composition ${ }^{1}$ of brewer's yeast with corn gluten meal

\begin{tabular}{lcc}
\hline Component, \% & Brewer's yeast & $\begin{array}{c}\text { Corn gluten } \\
\text { meal }\end{array}$ \\
& & $89.8 \pm 0.6$ \\
Dry matter & $96.30 \pm 0.8$ & $60.4 \pm 3.1$ \\
Crude protein & $44.9 \pm 2.7$ & $2.9 \pm 0.5$ \\
Ether extract & $2.1 \pm 1.2$ & $6.8 \pm 4.5$ \\
Neutral detergent fiber & $6.2 \pm 7.8$ & $1.9 \pm 1.7$ \\
Acid detergent fiber & $1.8 \pm 2.2$ & $2.2 \pm 0.4$ \\
Ash & $6.9 \pm 1.3$ & \\
\hline Amino acids (g/kg) & & $1.93 \pm 0.02$ \\
Arginine & $2.12 \pm 0.02$ & $1.10 \pm 0.01$ \\
Cysteine & $0.50 \pm 0.01$ & $1.20 \pm 0.02$ \\
Histidine & $0.93 \pm 0.01$ & $2.45 \pm 0.03$ \\
Isoleucine & $1.90 \pm 0.02$ & $10.04 \pm 0.05$ \\
Leucine & $2.75 \pm 0.03$ & $1.03 \pm 0.01$ \\
Lysine & $3.06 \pm 0.04$ & $1.51 \pm 0.02$ \\
Methionine & $0.62 \pm 0.01$ & $3.55 \pm 0.04$ \\
Phenylalanine & $1.71 \pm 0.02$ & $1.89 \pm 0.01$ \\
Threonine & $1.91 \pm 0.02$ & $2.79 \pm 0.02$ \\
Valine & $2.30 \pm 0.03$ & $0.01 \pm 0.1$ \\
Calcium & $0.37 \pm 0.3$ & $0.42 \pm 0.2$ \\
Phosphorus & $1.29 \pm 0.6$ & $3740 \pm 4.4$ \\
Metabolizable energy ${ }^{2}(\mathrm{kcal} / \mathrm{kg})$ & $2070 \pm 6.7$ & \\
\hline
\end{tabular}

${ }^{1}$ Analysed data in IBNA chemistry laboratory, ${ }^{2}$ Metabolizable Energy value was calculated based on regression equations (NRC, 1994). 
Table 2. Ingredient and nutrient composition of diets (as-fed basis)

\begin{tabular}{|c|c|c|c|c|c|c|}
\hline \multirow{3}{*}{ Diets } & \multicolumn{6}{|c|}{ Brewer's yeast levels as a substitute for CGM (\%) } \\
\hline & \multicolumn{3}{|c|}{$\begin{array}{c}\text { Starter } \\
(0-10 \text { days })\end{array}$} & \multicolumn{3}{|c|}{$\begin{array}{c}\text { Grower } \\
\text { (11-35 days) }\end{array}$} \\
\hline & $\mathbf{0}$ & 25 & 50 & $\mathbf{0}$ & 25 & 50 \\
\hline \multicolumn{7}{|l|}{ Ingredients (\%) } \\
\hline Corn & 55.89 & 54.81 & 53.79 & 56.73 & 56.14 & 54.83 \\
\hline SBM, $45.6 \%$ CP & 33.00 & 32.90 & 32.70 & 31.10 & 30.80 & 30.70 \\
\hline CGM, $60.7 \%$ CP & 4.30 & 3.22 & 2.15 & 4.30 & 3.22 & 2.15 \\
\hline $\mathrm{BY}, 44.3 \% \mathrm{CP}$ & 0.00 & 2.00 & 4.00 & 0.00 & 2.00 & 4.00 \\
\hline Soybean oil & 1.46 & 1.90 & 2.30 & 2.98 & 3.10 & 3.70 \\
\hline Monocalcium phosphate & 1.69 & 1.60 & 1.51 & 1.66 & 1.60 & 1.55 \\
\hline Calcium carbonate & 1.69 & 1.66 & 1.70 & 1.46 & 1.42 & 1.42 \\
\hline Salt & 0.28 & 0.28 & 0.28 & 0.28 & 0.28 & 0.28 \\
\hline L-lysine, 78\% & 0.33 & 0.27 & 0.21 & 0.18 & 0.13 & 0.06 \\
\hline Dl-methionine, 99\% & 0.28 & 0.28 & 0.28 & 0.23 & 0.23 & 0.23 \\
\hline Choline chloride & 0.08 & 0.08 & 0.08 & 0.08 & 0.08 & 0.08 \\
\hline Premix ${ }^{1}$ & 1.0 & 1.0 & 1.0 & 1.0 & 1.0 & 1.0 \\
\hline B. megaterium ${ }^{2}$ & $-/+$ & $-/+$ & $-/+$ & $-1+$ & $-/+$ & $-/+$ \\
\hline \multicolumn{7}{|l|}{ Calculated composition } \\
\hline $\mathrm{ME}, \mathrm{MJ} / \mathrm{kg}$ & 12.55 & 12.55 & 12.55 & 13.02 & 13.02 & 13.02 \\
\hline Crude protein & 23.0 & 23.0 & 23.0 & 22.0 & 22.0 & 22.0 \\
\hline Lysine, total & 1.41 & 1.41 & 1.41 & 1.24 & 1.24 & 1.24 \\
\hline Lysine, digestible & 1.28 & 1.27 & 1.27 & 1.16 & 1.14 & 1.13 \\
\hline Methionine, total & 0.65 & 0.65 & 0.66 & 0.59 & 0.60 & 0.60 \\
\hline Methionine, digestible & 0.63 & 0.63 & 0.63 & 0.57 & 0.58 & 0.58 \\
\hline TSAA, total & 1.02 & 1.02 & 1.02 & 0.95 & 0.95 & 0.95 \\
\hline TSAA, digestible & 0.94 & 0.94 & 0.94 & 0.87 & 0.88 & 0.88 \\
\hline Threonine & 0.80 & 0.83 & 0.86 & 0.76 & 0.79 & 0.83 \\
\hline Calcium & 1.00 & 1.00 & 1.00 & 0.90 & 0.90 & 0.90 \\
\hline Av. phosphorous & 0.45 & 0.45 & 0.45 & 0.45 & 0.45 & 0.45 \\
\hline Crude fat & 4.34 & 4.71 & 5.05 & 5.85 & 5.92 & 6.45 \\
\hline Crude fiber & 2.85 & 2.86 & 2.86 & 2.77 & 2.78 & 2.78 \\
\hline
\end{tabular}

Abbreviation: SBM, soybean meal; CGM, corn gluten meal; BY, Brewer's yeast; ME, metabolizable energy; TSAA, total sulphur amino acids.

${ }^{1}$ Supplied per kg diet: $12000 \mathrm{IU}$ vitamin A, $5000 \mathrm{IU}$ vitamin D3, $75 \mathrm{mg}$ vitamin E, $3 \mathrm{mg}$ vitamin $\mathrm{K}_{3}, 3$ mg vitamin $B_{1}, 8 \mathrm{mg}$ vitamin $B_{2}, 5 \mathrm{mg}$ vitamin $B_{6}, 0.016 \mathrm{mg}$ vitamin $B_{12}, 13 \mathrm{mg}$ pantothenic acid, 55 mg nicotinic acid, $2 \mathrm{mg}$ folic acid, $0.2 \mathrm{mg}$ biotin, $120 \mathrm{mg} \mathrm{Mn}, 100 \mathrm{mg} \mathrm{Zn,} 40 \mathrm{mg} \mathrm{Fe}, 16 \mathrm{mg} \mathrm{Cu}, 1.25 \mathrm{mg}$ I and $0.3 \mathrm{mg}$ Se, $70 \mathrm{mg}$ Monteban G100, $0.2 \mathrm{~g}$ Axtra PHY 5,000 L (1,000 FTU).

2 - = probiotic not included in the diet; + = probiotic included in the diet. 


\section{Criteria of Response}

In the 1,10, and 35 day of age, the body weight (BW) and feed intake (FI) of each replicate/group were noted. Records of BW and FI were used to calculate the FCR and body weight gain (BWG).

At 35 days of age, one bird was randomly selected from each replicate (6 birds/ treatment) for evaluation of carcass and visceral organ. Before slaughter, the feed was withdrawn for six hours to ensure that the digestive tract was empty. Thereafter, the birds were weighed, and slaughtered by neck cut, severing the right carotid artery and jugular vein. Immediately after slaughtered carcasses were de-feathered and eviscerated manually. The weight of the carcass, breast muscle, and legs without paws were determined. In addition, organs such as liver, heart, spleen, pancreas, and gizzard (removing skin, fat and connective tissue,) were excised, weighed, and expressed as relative weight to live BW. Finally, the intestine weight was done by emptying of its content. The length of the small intestine (duodenum, jejunum, ileum) and cecum were also measured and recorded. Muscle $\mathrm{pH}$ as measured at $30 \mathrm{~min}$. after slaughter. A portable digital $\mathrm{pH}$ meter (model HI 99163, Hanna Instruments, Romania) with a combined glass-penetrating electrode (FC 099 stainless steel blade tip) was calibrated using a 2-point method against standard buffer solutions $\mathrm{pH}$ values of 4.0 and 7.0. The $\mathrm{pH}$ value was expressed as the average of the 3 measurements.

Around $1 \mathrm{~g}$ of digesta from the cecum of the birds slaughtered at $35 \mathrm{~d}$ of age, was 10 -fold serially diluted with PBS medium (Oxoid Ltd.) and $10 \mu \mathrm{l}$ of the diluted sample was directly plated on the selective agar medium for enumeration of lactic acid bacteria (LAB) as well as Clostridium spp., Coliforms, Bacillus spp., and Enterococcus spp. Salmonella spp. and Escherichia coli (E. coli; biotype $\beta$-hemolytic), as described by Ciurescu et al. (2020). The microflora data were expressed as $\log _{10}$ CFU per gram of intestinal content.

On day 35 , the excreta were collected in sterile plastic bags and rapidly transported on ice to the laboratory. One gram of samples was diluted 1:9 $(\mathrm{w} / \mathrm{v})$ with distiller water in a beaker and vortex-homogenized for $2 \mathrm{~min}$. The $\mathrm{pH}$ values of the samples were determined with a portable $\mathrm{pH}$ meter (series pH 71 DHS, XS Instruments, Italy).

Feed samples were analyzed for dry matter (DM), crude protein (CP), ether extract (EE), ash, neutral detergent fiber, and acid detergent fiber following standard procedures (OJEU, 2009). A Fibertec apparatus (automatic system Foss-Tecator, Höganäs, Sweden) was used for determined the contents of neutral detergent fiber and acid detergent fiber. The regression equations from the NRC (1994) were applied for estimated the diets' metabolizable energy content based on individual feed ingredients. Amino acids (AA; without tryptophan) were analyzed using a highperformance liquid chromatography system (HPLC; Thermo Fisher Scientific 
Inc., San Jose, CA USA), fitted with a quaternary system for solvent pumping, and with photodiode array detectors (Surveyor PDA Plus Detector), according to the conditions described by Ciurescu et al. (2018). We used highly pure Hypersil GOLD silica chromatographic column designs to optimize separations and maximize productivity. AA standards certified purchased from Sigma-Aldrich were injected for the qualitative and quantitative determinations.

\section{Statistical Analysis data}

The data were subjected to two-way ANOVA using the GLM procedure of SPSS (version 20.0 for windows, SPSS Inc., Chicago, IL). Data were analysed as a $3 \times 2$ factorial arrangement of dietary treatment. The statistical model included the effects of Brewer's yeast levels (BY), probiotic addition (Pro), and their interactions. Replicate-pen was used as the experimental units for the analysis of GP (final BW, BWG, FI, and FCR), whereas data on the carcass and bacterial population of digesta (ceca) and excreta were based on individual broilers $(n=6)$. To separate means when interactive effects significantly differed, Tukey's post-hoc test was used. The results were expressed as treatment means with their pooled SEM. A P-value $<0.05$ was considered statistically significant, and P-value between 0.05 to 0.10 was classified as a tendency.

\section{RESULTS AND DISCUSSION}

\section{Nutrient composition of Brewer's yeast and corn-gluten meal}

As shown in Table 1, the CP content of Brewer's yeast is about $44.3 \%$ which is rather low than that in CGM (60.4\%). Moreover, around $20 \%$ of the $\mathrm{CP}$ in yeast corresponds to nucleic acids and nucleotides also (data not shown; Bacha et al., 2013). Studies have shown that the use of nucleotide in animal diets improve the morphology, function, and composition of intestinal microbiota, function and morphology of liver, immune response, as well as growth performance (Sauer et al., 2011).

Furthermore, although the total lysine, leucine, and arginine, BY's content is superior to that found in CGM, the standardized ileal digestibility (poultry) of all indispensable amino acids in BY is superior to in CGM (data not shown; Blok and Dekker, 2017). Brewer's yeast also contains much greater calcium and phosphorus and is a rich source of B vitamin (data not shown; NRC, 1994) compared with CGM.

\section{Productive performance}

The effects of BY (S. cerevisiae) level, Pro (B. megaterium) addition and interaction between level and probiotic on the GP (final BW, BWG, FI, and 
FCR) of broilers are shown in Table 3. Mortality was low $(<2.0 \%)$ and unrelated to treatment. There was no significant interaction between the main factors (BY $\times$ Pro) for all GP variables during the starter, grower phases and the overall period. Moreover, in the starter (days 1-10) periods of the trial, the results revealed that the broilers fed diets containing yeast at $25 \%$ or $50 \%$ instead of CGM had similar BWG. Also, FI and FCR were not significantly $(\mathrm{P}>0.05)$ affected by the dietary BY levels. During the grower (days 11-35) phase, the diets with BY levels up to 25\% generated BWG comparable with a diet containing CGM. Conversely, higher levels of BY (50\% replacing CGM) recorded the lowest value of BWG $(\mathrm{P}<0.001)$ and consequently impaired FCR ( $\mathrm{P}<0.010)$, but had no effect on FI $(\mathrm{P}>0.05)$. Over the entire feeding period, the poorest values of final BW $(\mathrm{P}<0.001)$ and FCR $(\mathrm{P}<0.010)$ were observed in chicks fed diets that contained $50 \% \mathrm{BY}$, whether supplemented with the Pro or not. However, BWG and FI were not significantly $(\mathrm{P}>0.05)$ affected by the dietary BY levels. The addition of Pro in broilers' diets was not effective in improving BWG, FI, and FCR, although the values of these variables were higher $(\mathrm{P}>0.05)$ compared to those from birds without Pro.

Reports related to improved poultry performance resulting from yeast culture (S. cerevisiae) are limited and inconsistent. Daghir and Abdul-Baki (1997) studied the broilers performance in the presence of yeast protein cultured on molasses to substitute part of the soybean meal and/or fish meal. They found that the yeast had the capacity to replace up to one-third of the soybean and all of the fish meal in the broiler diets if the methionine concentrations were balanced in all of the treatments applied. Aghdamshahriar et al. (2006) indicated that the use of yeast (S. cerevisiae) with 60 percent replacement of fish meal protein could improve broilers GP. Gao et al. (2017) and Ding et al. (2019) reported that the inclusion of yeast culture or yeast-derived products in broilers diets could improve BWG and FCR. Likewise, Zhang et al. (2019) noted that the dietary supplementation of $0.8 \%$ to $1 \%$ yeast culture (S. cerevisiae) increased average daily gain, but decreased FCR. In another research by Sousa et al. (2019) described that when broilers are fed with 6\% yeast resulted in higher BWG with lower FCR during the finisher period, but no differences were detected on FI in broilers. Contradictory, some researchers have observed that prebiotic yeast did not affect the growth response of poultry (Yalçinkaya et al., 2008; Munyaka et al., 2012). 
Table 3. Effects of dietary treatments on performance variables (mean values ${ }^{1}$ ) of broilers

\begin{tabular}{|c|c|c|c|c|c|c|c|c|c|c|c|c|}
\hline \multirow[t]{2}{*}{ Items } & \multirow[t]{2}{*}{ BY } & \multirow[t]{2}{*}{ Pro } & \multicolumn{3}{|c|}{ Starter (d 0-10) } & \multicolumn{3}{|c|}{ Grower (d 11-35) } & \multicolumn{4}{|c|}{ Overall (d 0-35) } \\
\hline & & & $\begin{array}{c}\text { BWG } \\
(\mathrm{g})\end{array}$ & $\begin{array}{c}\text { FI } \\
\text { (g) }\end{array}$ & $\begin{array}{c}\text { FCR } \\
(\mathrm{g} / \mathrm{g})\end{array}$ & $\begin{array}{c}\text { BWG } \\
(\mathrm{g})\end{array}$ & $\begin{array}{c}\text { FI } \\
\text { (g) }\end{array}$ & $\begin{array}{c}\text { FCR } \\
(\mathrm{g} / \mathrm{g})\end{array}$ & $\begin{array}{l}\text { BW } \\
\text { (g) }\end{array}$ & $\begin{array}{c}\text { BWG } \\
\text { (g) }\end{array}$ & $\begin{array}{c}\text { FI } \\
\text { (g) }\end{array}$ & $\begin{array}{c}\text { FCR } \\
(\mathrm{g} / \mathrm{g})\end{array}$ \\
\hline 1 & 0 & No & 235 & 289 & 1.23 & 1869 & 3066 & 1.64 & 2149 & 2104 & 3455 & 1.64 \\
\hline 2 & 25 & No & 231 & 287 & 1.24 & 1881 & 3073 & 1.63 & 2157 & 2112 & 3440 & 1.63 \\
\hline 3 & 50 & No & 229 & 282 & 1.23 & 1808 & 3040 & 1.68 & 2082 & 2037 & 3428 & 1.68 \\
\hline 4 & 0 & Yes & 236 & 291 & 1.23 & 1887 & 3060 & 1.62 & 2168 & 2123 & 3463 & 1.63 \\
\hline 5 & 25 & Yes & 234 & 290 & 1.24 & 1922 & 3085 & 1.61 & 2201 & 2156 & 3488 & 1.62 \\
\hline 6 & 50 & Yes & 233 & 289 & 1.24 & 1845 & 3047 & 1.65 & 2124 & 2078 & 3436 & 1.65 \\
\hline SEM $^{3}$ & & & 4.57 & 6.33 & 0.01 & 7.78 & 22.78 & 0.01 & 17.44 & 15.52 & 26.98 & 0.01 \\
\hline \multicolumn{13}{|c|}{ Main effects ${ }^{4}$} \\
\hline 0 & & & 236 & 290 & 1.23 & $1878^{\mathrm{a}}$ & 3063 & $1.63^{\mathrm{a}, \mathrm{b}}$ & $2158^{\mathrm{a}}$ & 2114 & 3459 & $1.63^{\mathrm{a}, \mathrm{b}}$ \\
\hline 25 & & & 233 & 289 & 1.24 & $1901^{\mathrm{a}}$ & 3079 & $1.62^{\mathrm{b}}$ & $2179^{a}$ & 2134 & 3464 & $1.62^{\mathrm{b}}$ \\
\hline 50 & & & 231 & 286 & 1.24 & $1826^{b}$ & 3044 & $1.67^{\mathrm{a}}$ & $2103^{b}$ & 2103 & 3432 & $1.67^{\mathrm{a}}$ \\
\hline \multicolumn{13}{|c|}{ Pro addition } \\
\hline No & & & 232 & 286 & 1.23 & 1853 & 3060 & 1.65 & 2129 & 2084 & 3441 & 1.65 \\
\hline Yes & & & 234 & 290 & 1.24 & 1885 & 3064 & 1.63 & 2164 & 2119 & 3462 & 1.63 \\
\hline \multicolumn{13}{|l|}{ P-value } \\
\hline BY effect & & & 0.454 & 0.322 & 0.347 & 0.001 & 0.455 & 0.010 & 0.001 & 0.208 & 0.546 & 0.010 \\
\hline Pro effec & & & 0.232 & 0.338 & 0.349 & 0.123 & 0.556 & 0.167 & 0.118 & 0.133 & 0.364 & 0.117 \\
\hline $\mathrm{BY} \times$ Pro & ffect & & 0.898 & 0.877 & 0.754 & 0.556 & 0.843 & 0.892 & 0.727 & 0.851 & 0.726 & 0.648 \\
\hline
\end{tabular}

Abbreviation: BY, Brewer's yeast; Pro, probiotic (B. megaterium).

${ }^{1}$ Data are means of 6 replicate pens with 20 birds per pen. ${ }^{2}$ SEM, standard error of the mean. ${ }^{3}$ Data were analyzed as a $3 \times 2$ factorial arrangement.

a,b Means with different superscripts in a row differ significantly $(\mathrm{P}<0.05), \mathrm{T}=$ tendency to be influenced by treatment. 
The reason behind these differences in research findings could be associated to differences in the breed of bird used, ingredient/ diet composition, form or type, as well as the level of yeast product inclusion in poultry diet. The results in the present study revealed that BY (at level up to $25 \%$, replacing CGM) can show a prebiotic effect that led to improved broiler performance. To the best of our knowledge, there is no study on the effects of $B$. megaterium as Pro on broilers performance. Our previous work has shown that probiotic supplementation (B. subtilis ATCC 6051a strain) may improve BWG and feed efficiency in birds (Ciurescu et al., 2020). In the present study, the addition of $B$. megaterium as Pro in diets with high BY levels (to replace CGM) did not improve growth performance significantly. However, the values of BWG were higher $(\mathrm{P}>0.05)$ compared to those from birds without Pro.

\section{Carcass traits}

The effect of BY and Pro addition on carcass, breast and legs' yield, organ weights (i.e., heart, gizzard, liver, spleen, pancreas, small intestine, and cecum) as well as cecum and small intestine length, and $\mathrm{pH}$ of breast muscle of birds are presented in Table 4. No significant interaction between the main factors (BY $\times$ Pro) was noted for all carcass characteristics measured, except for breast muscle $\mathrm{pH}$, gizzard, and spleen weight $(\mathrm{P}=0.041 ; \mathrm{P}=0.005$ and $\mathrm{P}=0.005$, respectively). Feeding broilers up to 35 days of age with BY diets did not significantly affect the main traits of the carcass, except for gizzard, whose weights have improved $(\mathrm{P}=0.005)$, compared with birds fed CGM diets. Likewise, no difference was noted on the carcass and organs size when diets were supplemented with Pro; only a tendency to increase the gizzard weight $(\mathrm{P}=0.094)$ and decrease SIL $(\mathrm{P}=0.076)$ was observed.

Our results concur with the comments of Waldroup et al. (2003), who did not observe any significant impact of yeast mannan oligosaccharide product (MOS) on carcass and meat yield (breast, thighs, and drumsticks) of broiler chickens. On the contrary, Paryad and Mahmoudi (2008) noticed that the $1.5 \%$ and $2 \%$ S. cerevisiae inclusion significantly enhanced the carcass and the meat yield of broiler chickens at $\mathrm{d} 42$. More like that, Abdelrahman (2013) showed that yeast culture $(3 \mathrm{~kg} / \mathrm{t})$ to diets containing dry fat improves broiler growth performance and positively affects the carcass characteristics by reducing the abdominal fat. Likewise, Ahiwe et al. (2020) reported that dietary supplementation with whole yeast and yeast cell walls (1.5-2 g/kg feed) could improve GP and meat yield in broilers. Furthermore, Abdel-Hafeez et al. (2017) reported that supplementation of broiler diets with three kinds of additives (prebiotic, probiotic or symbiotic) have a positive effect on gizzard and proventriculus relative weight, spleen, bursa of Fabricius, and the two ceca (except the probiotic). 
Table 4. Effects of dietary treatments on the relative carcass and organ weight (mean values ${ }^{1}$ ) of broilers (\%)

\begin{tabular}{|c|c|c|c|c|c|c|c|c|c|c|c|c|c|c|}
\hline \multirow[t]{2}{*}{ Items } & \multirow[t]{2}{*}{ BY } & \multirow[t]{2}{*}{ Pro } & \multirow[t]{2}{*}{ Carcass } & \multicolumn{2}{|c|}{ Breast } & \multirow[t]{2}{*}{ Leg } & \multicolumn{6}{|c|}{ Organs } & \multirow[t]{2}{*}{ SIL } & \multirow{2}{*}{$\begin{array}{l}\text { Cecum } \\
\text { length }\end{array}$} \\
\hline & & & & yield & $\mathrm{pH}$ & & Liver & Gizzard & Heart & Spleen & Pancreas & SIW & & \\
\hline 1 & 0 & No & 75.31 & 41.24 & 5.95 & 27.50 & 2.39 & 1.69 & 0.57 & 0.14 & 0.27 & 3.82 & 8.93 & 1.51 \\
\hline 2 & 25 & No & 75.45 & 41.49 & 6.06 & 26.75 & 2.38 & 1.77 & 0.60 & 0.19 & 0.26 & 4.11 & 9.27 & 1.51 \\
\hline 3 & 50 & No & 75.63 & 41.86 & 5.97 & 26.20 & 2.43 & 2.08 & 0.54 & 0.13 & 0.27 & 4.00 & 9.50 & 1.51 \\
\hline 4 & 0 & Yes & 75.49 & 41.46 & 6.07 & 27.29 & 2.42 & 2.07 & 0.60 & 0.15 & 0.24 & 3.56 & 7.90 & 1.51 \\
\hline 5 & 25 & Yes & 75.87 & 42.02 & 5.84 & 26.83 & 2.46 & 1.64 & 0.53 & 0.14 & 0.28 & 3.65 & 8.84 & 1.51 \\
\hline 6 & 50 & Yes & 75.26 & 41.66 & 6.02 & 27.46 & 2.36 & 2.31 & 0.58 & 0.15 & 0.28 & 3.61 & 9.04 & 1.51 \\
\hline SEM $^{2}$ & & & 0.92 & 0.21 & 0.03 & 0.17 & 0.17 & 0.06 & 0.01 & 0.01 & 0.01 & 0.08 & 0.18 & 0.05 \\
\hline \multicolumn{15}{|c|}{ Main effects ${ }^{3}$} \\
\hline \multicolumn{15}{|c|}{ BY level } \\
\hline 0 & & & 75.40 & 41.35 & 6.00 & 27.39 & 2.40 & $1.88^{\mathrm{a}}$ & 0.58 & 0.15 & 0.25 & 3.69 & 8.41 & 1.57 \\
\hline 25 & & & 75.65 & 41.86 & 5.95 & 26.79 & 2.42 & $1.70^{\mathrm{b}}$ & 0.57 & 0.16 & 0.27 & 3.88 & 9.06 & 1.80 \\
\hline 50 & & & 75.45 & 41.76 & 5.99 & 26.83 & 2.39 & $2.19^{a}$ & 0.56 & 0.14 & 0.27 & 3.81 & 9.27 & 1.63 \\
\hline \multicolumn{15}{|c|}{ Pro addition } \\
\hline No & & & 75.46 & 41.53 & 6.00 & 26.81 & 2.39 & 1.85 & 0.56 & 0.16 & 0.26 & $3.98^{\mathrm{a}}$ & 9.24 & 1.66 \\
\hline Yes & & & 75.54 & 41.78 & 5.97 & 27.19 & 2.42 & 2.00 & 0.57 & 0.15 & 0.27 & $3.61^{\mathrm{b}}$ & 8.60 & 1.67 \\
\hline \multicolumn{15}{|l|}{ P-value } \\
\hline BY effe & & & 0.332 & 0.597 & 0.707 & 0.255 & 0.967 & 0.005 & 0.967 & 0.141 & 0.527 & 0.606 & 0.128 & 0.136 \\
\hline Pro effe & & & 0.543 & 0.568 & 0.689 & 0.256 & 0.745 & $0.094^{\mathrm{T}}$ & 0.745 & 0.432 & 0.978 & 0.024 & $0.076^{\mathrm{T}}$ & 0.923 \\
\hline $\mathrm{BY} \times \mathrm{Pr}$ & effect & & 0.687 & 0.232 & 0.041 & 0.686 & 0.658 & 0.005 & 0.658 & 0.005 & 0.536 & 0.858 & 0.734 & 0.695 \\
\hline
\end{tabular}

Abbreviation: BY, Brewer's yeast; Pro, probiotic (B. megaterium); SIW, small intestine weight; SIL, small intestine length.

${ }^{1}$ Data are means of 6 replicate pens with 20 birds per pen. ${ }^{2}$ SEM, standard error of the mean. ${ }^{3}$ Data were analyzed as a $3 \times 2$ factorial arrangement.

a,b Means with different superscripts in a row differ significantly $(\mathrm{P}<0.05), \mathrm{T}=$ tendency to be influenced by treatment. 
The microflora of intestinal digesta and excreta

Yeast has a role in reducing gut $\mathrm{pH}$ via the production of a wide range of organic acids resulting in an acidic environment in the intestine and ultimate inhibition in the growth of pathogenic bacteria in the intestine (Ogbuewu et al., 2019).

The effect of treatments on the microbial populations of intestinal digesta and excreta, and $\mathrm{pH}$ value are shown in Table 5. The interaction between the main factors (BY $\times$ Pro) had no effect on microbial populations of cecal digesta and excreta of broilers at 35 days of age, except for Enterococcus spp., whose numbers have increased $(\mathrm{P}=0.001)$ in the caecum and tended $(P=0.098)$ to lower the coliforms count in excreta. The cecal digesta assay results show that $\mathrm{pH}$ value significantly declines $(\mathrm{P}<0.010)$ as well as total coliforms, Clostridium spp., and E. coli bacteria $(P=0.027 ; \mathrm{P}<$ 0.010 and $\mathrm{P}<0.0001$, respectively), whereas Bacillus spp. increases $(\mathrm{P}<$ 0.0001 ) by dietary inclusion of BY (to replace CGM). Nevertheless, LAB and Enterococcus spp. populations were not affected by dietary treatments.

B. megaterium addition as Pro, significantly decreased $(\mathrm{P}=0.040)$ the $\mathrm{pH}$ value of cecal digesta. Furthermore, birds fed with Pro diets showed a significant decrease of coliforms $(\mathrm{P}<0.010)$, Clostridium spp. $(P<0.0001)$, and E. coli $(\mathrm{P}<0.0001)$ in the caecum content, whereas LAB, Bacillus spp., and Enterococcus spp. numbers were increased $(\mathrm{P}=0.022 ; \mathrm{P}<0.0001$, and $\mathrm{P}$ $<0.0001$, respectively), compared with diets without Pro.

As shown in Table 5, the excreta Bacillus spp. and Enterococcus spp. population in the BY treatments was higher $(\mathrm{P}<0.0001$ and $\mathrm{P}<0.0001$, respectively), whereas total coliforms and Clostridium spp. bacteria was lowest $(P<0.010$ and $P<0.0001$, respectively). Moreover, there was a tendency to decrease the $E$. coli bacteria $(P=0.084)$ in broilers excreta. Likewise, B. megaterium as Pro in broilers diet increased excreta Bacillus spp. and Enterococcus spp. population $(\mathrm{P}<0.0001$ and $\mathrm{P}<0.0001$, respectively), whereas total coliforms, Clostridium spp., and E. coli bacteria was decreased $(P<0.0001 ; P<0.0001$ and $P<0.0001$, respectively). The results, also showed a tendency to reduce the $\mathrm{pH}$ value $(\mathrm{P}=0.057)$ from excreta at 35 days of age. Nevertheless, LAB counts remained comparable among Pro broilers' diets. Our findings agreed with those of Elghandour et al. (2019), who documented that $S$. cerevisiae could reduce the $\mathrm{pH}$ values of the broiler gut. Moreover, the authors noted that yeast supplementation involved the production of broilers performances and chickens' resistance to enteric pathogens infection (Campylobacter jejuni, C. perfringens, E. coli, Salmonella etc.). It was also reported that supplementation diets with yeast (S. cerevisiae) had been shown to modulate the birds' intestinal microflora to inhibit the colonization of GIT by bacterial pathogens (Haldar et al., 2011; Javadi et al., 2012). 
Table 5. Effects of dietary treatments on the digesta and excreta microflora $\left(\log _{10} \mathrm{CFU} / \mathrm{g}\right)$ and $\mathrm{pH}$ values (mean values $\left.{ }^{1}\right)$ of broilers

\begin{tabular}{|c|c|c|c|c|c|c|c|c|c|c|c|c|c|c|c|c|}
\hline \multirow[t]{2}{*}{ Items } & \multirow[t]{2}{*}{ BY } & \multirow[t]{2}{*}{ Pro } & \multicolumn{7}{|c|}{ Caecal digesta } & \multicolumn{7}{|c|}{ Excreta } \\
\hline & & & LAB & $\begin{array}{l}\text { Bacillus } \\
\text { spp. }\end{array}$ & Coliforms & $\begin{array}{l}\text { Clostridium } \\
\text { spp. }\end{array}$ & $\begin{array}{c}\text { Entero } \\
\text { coccus } \\
\text { spp. }\end{array}$ & $\begin{array}{c}E \\
\text { coli }\end{array}$ & pH & LAB & $\begin{array}{l}\text { Bacillus } \\
\text { spp. }\end{array}$ & Coliforms & $\begin{array}{l}\text { Clostridium } \\
\text { spp. }\end{array}$ & $\begin{array}{c}\text { Entero } \\
\text { coccus } \\
\text { spp. }\end{array}$ & E. coli & pH \\
\hline 1 & 0 & No & 8.05 & 2.38 & 6.42 & 6.56 & 5.65 & 4.17 & 6.08 & 8.09 & 2.30 & 6.83 & 6.36 & 6.40 & 9.33 & 6.99 \\
\hline 2 & 25 & No & 7.60 & 3.33 & 5.91 & 6.41 & 5.84 & 3.65 & 5.87 & 7.98 & 2.55 & 7.00 & 4.77 & 5.91 & 8.87 & 6.95 \\
\hline 3 & 50 & No & 8.19 & 3.38 & 6.27 & 6.85 & 6.31 & 3.76 & 5.82 & 8.21 & 2.16 & 6.27 & 5.03 & 6.43 & 8.92 & 6.87 \\
\hline 4 & 0 & Yes & 8.28 & 3.55 & 5.73 & 5.82 & 5.87 & 3.94 & 5.80 & 8.43 & 4.35 & 5.90 & 4.72 & 6.76 & 7.92 & 6.83 \\
\hline 5 & 25 & Yes & 8.61 & 3.79 & 5.70 & 5.26 & 6.45 & 2.63 & 5.76 & 8.27 & 4.88 & 5.41 & 4.00 & 6.80 & 8.22 & 6.76 \\
\hline 6 & 50 & Yes & 8.42 & 3.58 & 5.52 & 5.39 & 7.30 & 2.09 & 5.43 & 8.04 & 4.33 & 5.96 & 5.00 & 7.47 & 7.76 & 6.79 \\
\hline \multicolumn{3}{|c|}{$\mathrm{SEM}^{2}$} & 0.17 & 0.33 & 0.19 & 0.17 & 0.13 & 0.22 & 0.12 & 0.11 & 0.24 & 0.15 & 0.15 & 0.12 & 0.26 & 0.28 \\
\hline \multicolumn{17}{|c|}{$\begin{array}{l}\text { Main effects } \\
\text { BY level }\end{array}$} \\
\hline 0 & & & 8.16 & $2.97^{b}$ & $6.08^{\mathrm{a}}$ & $6.19^{a}$ & 5.75 & $4.05^{\mathrm{a}}$ & $5.94^{\mathrm{a}}$ & 8.26 & $3.33^{\mathrm{a}}$ & $6.36^{\mathrm{a}}$ & $5.54^{\mathrm{a}}$ & $6.58^{\mathrm{b}}$ & 8.63 & 6.89 \\
\hline 25 & & & 8.11 & $3.56^{\mathrm{a}}$ & $5.80^{\mathrm{b}}$ & $5.84^{\mathrm{b}}$ & 5.84 & $3.14^{\mathrm{b}}$ & $5.82^{\mathrm{a}}$ & 8.12 & $3.72^{\mathrm{a}}$ & $6.45^{\mathrm{a}}$ & $4.39^{c}$ & $6.36^{c}$ & 8.55 & 6.86 \\
\hline 50 & & & 8.31 & $3.48^{\mathrm{a}}$ & $5.89^{\mathrm{b}}$ & $6.12^{\mathrm{a}}$ & 5.86 & $2.93^{c}$ & $5.63^{\mathrm{b}}$ & 8.13 & $3.25^{\mathrm{b}}$ & $6.11^{\mathrm{b}}$ & $5.01^{\mathrm{b}}$ & $6.95^{\mathrm{a}}$ & 8.34 & 6.83 \\
\hline \multicolumn{17}{|c|}{ Pro addition } \\
\hline No & & & $7.95^{\mathrm{b}}$ & $3.03^{\mathrm{b}}$ & $6.20^{\mathrm{a}}$ & $6.60^{\mathrm{a}}$ & $5.95^{\mathrm{b}}$ & $3.86^{\mathrm{a}}$ & $5.92^{\mathrm{a}}$ & 8.09 & $2.34^{\mathrm{b}}$ & $6.70^{\mathrm{a}}$ & $5.39^{\mathrm{a}}$ & $6.25^{\mathrm{b}}$ & $9.04^{\mathrm{a}}$ & 6.94 \\
\hline \multirow{2}{*}{\multicolumn{17}{|c|}{ P-value }} \\
\hline & & & & & & & & & & & & & & & & \\
\hline Pro effe & & & 0.022 & 0.000 & 0.010 & 0.000 & 0.000 & 0.000 & 0.040 & 0.111 & 0.000 & 0.000 & 0.000 & 0.000 & 0.000 & $0.057^{\mathrm{T}}$ \\
\hline $\mathrm{BY} \times \operatorname{Pr}$ & effect & & 0.597 & 0.571 & 0.495 & 0.667 & 0.000 & 0.598 & 0.897 & 0.614 & 0.771 & $0.098^{\mathrm{T}}$ & 0.564 & 0.831 & 0.777 & 0.410 \\
\hline
\end{tabular}

Abbreviation: BY, Brewer's yeast; Pro, probiotic (B. megaterium).

${ }^{1}$ Data are means of 6 replicate pens with 20 birds per pen. ${ }^{2}$ SEM, standard error of the mean. ${ }^{3}$ Data were analyzed as a $3 \times 2$ factorial arrangement.

a,b,cMeans with different superscripts in a row differ significantly $(\mathrm{P}<0.05), \mathrm{T}=$ tendency to be influenced by treatment. 
In the present study, the inclusion of $B$. megaterium as Pro in broilers' diets reduced the $\mathrm{pH}$ value of cecal digesta and total coliforms, Clostridium spp., and E. coli bacteria, whereas LAB, Bacillus spp., and Enterococcus spp. population were increased. Until now, there are no studies reporting the effects of $B$. megaterium in broilers diet on bacterial population. Previous studies have exposed that Bacillus spp.-based probiotics diets (B. coagulans or $B$. subtilis) increases the beneficial bacteria, following by a decrease of pathogens, improving also, the growth performance and carcass quality in broiler chickens (Hung et al., 2012; Gao et al., 2017; Li et al., 2017; Reis et al., 2017; Ciurescu et al., 2020).

\section{CONCLUSION}

Brewers' yeast ( $S$. cerevisiae) as a protein source can replace CGM (up to $25 \%$ ) in the broiler feeds formulation to support growth performance, carcass and internal organs characteristics without any detrimental effects on birds. Furthermore, BY derived from $S$. cerevisiae enhances the GIT microflora and reduces pathogens, especially $E$. coli. Therefore, we consider that its use as a feed ingredient should be encouraged where breweries are situated, especially in Romania. It also has the advantage of lower costs of feeds when used up to this level; therefore, its use will provide cheaper and healthy birds for consumers and improve profits for poultry farmers.

B. megaterium supplementation positively affect the GIT and excreta microflora of broilers. In the light of these results and the limitations of the present study, additional work will be carried out to develop suitable ways to utilize the $B$. megaterium strain in the broiler feeds as an alternative to antibiotics.

\section{ACKNOWLEDGEMENTS}

This study was sponsored by the Romanian Ministry of Research, Innovation and Digitization over the Nucleus program (PN19-09.01.04 project).

\section{REFERENCES}

Abdel-Hafeez, H.M., Saleh, E.S., Tawfeek, S.S., Youssef, I.M.I., and A.S.A. AbdelDaim. 2017. Effect of probiotic, prebiotic, and symbiotic with and without feed restriction on performance, hematological indices and carcass characteristics of broiler chickens. Asian-Austral J. Anim. Sci. 30: 672-682. Abdelrahman, M.M. 2013. Effects of feeding dry fat and yeast culture on broiler chicken performance. Turkish J. Vet. Anim. Sci. 37: 31-37. Ahiwe, E.U., Abdallh, M.E., Chang'a, E.P., Omede, A.A., Al-Qahtani, A., Gausi, H.,

Graham, H., and P.A. Iji. 2020. Influence of dietary supplementation of 
autolyzed whole yeast and yeast cell wall products on broiler chickens. Asian-Australas J. Anim. Sci. 33(4): 579-587.

Amorim, M., Pereira, J. O., Gomes, D., Pereira, C.D., Pinheiro, H., and M. Pintado. 2016. Nutritional ingredients from spent brewer's yeast obtained by hydrolysis and selective membrane filtration integrated in a pilot process. J. Food Eng. 185: 42-47.

Aghdamshahriar, H., Nazer-adl, A., and A. Ahmadzadeh. 2006. The effect of yeast (Saccharomyces cerevisiae) in replacement fish meal and poultry by product protein in broiler diets. XII European Poultry Conference, Verona, Italia.

Bacha, U., Nasir, M., Ali, M.A., Muhammad, J., and A.A Sheikh. 2013. Review article: nucleotides supplementation improves various function of the body. J. Anim. Health Prod. 1: 1-5.

Blok, M.C. and R. A. Dekker. 2017. Table 'Standardized ileal digestibility of amino acids in feedstuffs for poultry'. CVB Documentation report nr. 61 .

Ciurescu, G., Dumitru, M., Gheorghe, A., Untea, A.E., and R. Drăghici. 2020. Effect of Bacillus subtilis on growth performance, bone mineralization, and bacterial population of broilers fed with different protein sources. Poult. Sci. 99(11): 5960-5971.

Ciurescu, G., Toncea, I., Ropota, M. and M. Hăbeanu. 2018. Seeds composition and their nutrients quality of some pea (Pisum sativum L.) and lentil (Lens culinaris Medik.) cultivars. Rom. Agricult. Res. 35: 101-108.

Chen, C.Y., Chen, S.W., and H.T. Wang. 2017. Effect of supplementation of yeast with bacteriocin and Lactobacillus culture on growth performance, caecal fermentation, microbiota composition, and blood characteristics in broiler chickens. Asian-Australasian J. Anim. Sci. 3: 211-220.

Chollom, P.F., Okojokwu, O.J., Egbere, O.J., Ikeji, F.N., Yisa, A.G., Doma, U.D., and E.B. Agbo. 2017. Use of Spent Brewers' Yeast (Saccharomyces cerevisiae) in Feeds to Replace Soya Bean on Performance, Carcass Characteristics and Internal Organs of Broiler Chickens. Researcher, 9(6): 40-44.

Daghir, N.J., and T.K. Abdul-Baki. 1997. Yeast protein in broiler rations. Poult. Sci. 56: 1836-1841.

Ding, B., Zheng, J., Wang, X., Zhang, L., Sun, D., Xing, Q., Pirone, A., and B. Fronte. 2019. Effects of dietary yeast beta-1,3-1,6-glucan on growth performance, intestinal morphology and chosen immunity parameters changes in Haidong chicks. Asian-Australas J. Anim. Sci. 32: 1558-1564.

Dos Santos Mathias, T.R., de Mello, P.P.M., and E.F.C Servulo. 2014. Solid wastes in brewing process: a review. J. Brew. Distilling. 5: 1-9.

Dumitru, M., Lefter, N., Idriceanu, L., Ciurescu, G., and M. Habeanu. 2021. Identification and characterization of Bacillus megaterium as probiotic bacteria in poultry feed. Scientific Papers: Animal Science and Biotechnologies (in press). 
Elghandour, M.M.Y., Tan, Z.L., Abu Hafsa, S.H., Adegbeye, M.J., Greiner, R., Ugbogu, E.A., Cedillo Monroy, J., and A.Z.M Salem. 2019. Saccharomyces cerevisiae as a probiotic feed additive to non and pseudo-ruminant feeding: A review. J. Appl. Microbiol., 128(3): 658-674.

Gadde, U., Kim, W. H., Oh, S. T., Lillehoj, H. S. 2017. Alternatives to antibiotics for maximizing growth performance and feed efficiency in poultry: a review. - Animal Health Research Reviews 18(1): 26-45.

Gao, Z., Wu, H., Shi, L., Zhang, X., Sheng, R., Yin, F., and R. Gooneratne. 2017. Study of Bacillus subtilis on growth performance, nutrition metabolism and intestinal microflora of 1 to $42 \mathrm{~d}$ broiler chickens. Anim. Nutr. 3: 109113.

Haldar, S., Ghosh, T.K., Toshiwati, T.K., and M.R. Bedford. 2011. Effects of yeast (Saccharomyces cerevisiae) and yeast protein concentrate on production performance of broiler chickens exposed to heat stress and challenged with Salmonella enteritidis. Anim. Feed Sci. Technol. 168: 61-71.

Hung, A., Lin, S.Y., Yang, T.Y., Chou, C.K., Liu, H.C., Lu, J.J., Wang, B., Chen, S.Y., and T.F. Lien. 2012. Effects of Bacillus coagulans ATCC 7050 on growth performance, intestinal morphology, and microflora composition in broiler chickens. Anim. Prod. Sci. 52: 874-879.

Javadi, A., Mirzaei, H., Safarmashaei, S., and S. Vahdatpour. 2012. Effects of probiotic (live and inactive Saccharomyces cerevisiae) on meat and intestinal microbial properties of Japanese quails. Afr. J. Biotechnol. 11: 12083-12087.

Kim, G.B., Seo, Y.M., Kim, C.H., and I.K. Paik. 2011. Effect of dietary prebiotic supplementation on the performance, intestinal microflora, and immune response of broilers. Poult. Sci. 90(1): 75-82.

Li, Z., Wang, W., Lv, Z., Liu, D., and Y. Guo. 2017. Bacillus subtilis and yeast cell wall improve the intestinal health of broilers challenged by Clostridium perfringens. Br. Poult. Sci. 58(6): 635-643.

Mountzouris, K.C., Tsirtsikos, P., Palamidi, I., Arvaniti, A., Mohnl, M., Schatzmayr, G., and K. Fegeros. 2010. Effects of probiotic inclusion levels in broiler nutrition on growth performance, nutrient digestibility, plasma immunoglobulins, and cecal microflora composition. Poult. Sci. 89: 58-67.

Mountzouris, K.C., Tsirtsikos, P., Kalamara, E., Nitsh, S., Schatzmayr, G., and K. Fegeros. 2007. Evaluation of the efficacy of a probiotic containing Lactobacillus, Bifidobacterium, Enterococcus, and Pediococcus strains in promoting broiler performance and modulating cecal microflora composition and metabolic activities. Poult. Sci. 86(2): 309-317.

Munyaka, P.M., Echeverry, H., Yitbarek, A., Camelo-Jaimes, G., Sharif, S., Guenter, W. House, J.D. and J.C. Rodriguez Lecompte. 2012. Local and systemic innate immunity in broiler chickens supplemented with yeastderived carbohydrates. Poult. Sci. 91(9): 2164-2172. 
Muthusamy, N., Haldar, S., Ghosh, T.K., and M.R., Bedford. 2011. Effects of hydrolysed Saccharomyces cerevisiae yeast and yeast cell wall components on live performance, intestinal histo-morphology and humoral immune response of broilers. Br. Poult. Sci., 52: 694-703.

National Research Council. 1994. Nutrient Requirements of Poultry, 9th rev. Natl. Acad. Press, Washington, DC.

Official Journal of the European Union (OJEU L 54), 2009. Commission Regulation (EC) No. 152/2009 Laying Down the Methods of Sampling and Analysis for the Official Control of Feed.

Ogbuewu, I.P., Okoro, V.M., Mbajiorgu, E.F., and C.A. Mbajiorgu. 2019. Yeast (Saccharomyces cerevisiae) and its effect on production indices of livestock and poultry - a review. Comp. Clin. Path. 51(2): 669-677.

Park, J. H., and I. H. Kim. 2014. Supplemental effect of probiotic Bacillus subtilis B2A on productivity, organ weight, intestinal Salmonella microflora, and breast meat quality of growing broiler chicks. Poult. Sci. 93(8): 20542059.

Paryad, A, and M. Mahmoudi. 2008. Effect of different levels of supplemental yeast (Saccharomyces cerevisiae) on performance, blood constituents and carcass characteristics of broiler chicks. Afr. J. Agric. Res. 3: 835-42.

Reis, M.P., Fassani, E.J., Garcia Júnior, A.A.P., Rodrigues, P.B., Bertechini, A.G., Barrett, N., and C.J. Schmidt. 2017. Effect of Bacillus subtilis (DSM 17299) on performance, digestibility, intestine morphology, and $\mathrm{pH}$ in broiler chickens. J. Appl. Poult. Res. 26: 573-583.

Sauer, N., Mosenthin, R., and E. Bauer. 2011. The role of dietary nucleotides in single-stomached animals. Nutr. Res. Rev. 24: 46-59.

Sen, S., Ingale, S.L., Kim, Y.W., Kim, J.S, Kim, K.H., Lohakare, J.D., Kim, E.K., Kim, H.S., Ryu, M.H., Kwon, I.K., and B.J. Chae. 2012. Effect of supplementation of Bacillus subtilis LS 1-2 to broiler diets on growth performance, nutrient retention, caecal microbiology and small intestinal morphology. Res. Vet. Sci. 93: 264-268.

Silva, V.K., Silva, J.D.T.D., Gravena, R.A., Marques, R.H., Hada, F.H., and V.M.B.D. Moraes. 2010. Yeast extract and prebiotic in pre-initial phase diet for broiler chickens raised under different temperatures. Rev. Bras. Zootec. 39: 165-174.

Sousa, R.F., Dourado, L.R.B., Lopes, J.B., Fernandes, M.L., Kato, R.K., Nascimento, D.C.N., Sakomura, N.K., Lima, S.B.P., and G.J.B.C. Ferreira. 2019. Effect of an enzymatic blend and yeast on the performance, carcass yield and histomorphometry of the small intestine in broilers from 21 to 42 days of age. Braz. J. Poult. Sci. 21: 1-6.

Zhang, A.W., Lee, B.D., Lee, S.K., Lee, K.W., An, G.H., Song, K.B., and C.H. Lee. 2005. Effects of yeast (Saccharomyces cerevisiae) cell components on growth performance, meat quality, and ileal mucosa development of broiler chicks. Poult. Sci. 84(7): 1015-1021. 
Zhen, W., Shao, Y., Gong, X., Wu, Y., Geng, Y., Wang, Z., and Y. Guo. 2018. Effect of dietary Bacillus coagulans supplementation on growth performance and immune responses of broiler chickens challenged by Salmonella enteritidis. Poult. Sci. 97(8): 2654-2666.

Zhou, M., Liang, R., Mo, J., Yang, S., Gu, N., Wu, Z., Sarath Babu, V., Li, J., Huang, Y.M., and L. Lin. 2018. Effects of brewer's yeast hydrolysate on the growth performance and the intestinal bacterial diversity of largemouth bass (Micropterus salmoides). Aquaculture. 484: 139-144.

Waldroup, P. W., Fritts, C. A., and F. Yan. 2003. Utilization of biomos mannan oligosaccharide and Bioplex cooper in broiler diets. Int. J. Poult. Sci. 2: 4452.

Yalçinkaya, İ., Guengoer, T., Başalan, M., and E. Erdem. 2008. Mannan oligosaccharides (MOS) from Saccharomyces cerevisiae in broilers: Effects on performance and blood biochemistry. Turk. J. Vet. Anim. Sci. 32: 43-48. 